\title{
European clinical guidelines for Tourette Syndrome and other tic disorders
}

\author{
Veit Roessner - Aribert Rothenberger • \\ Hugh Rickards · Pieter J. Hoekstra
}

(C) The Author(s) 2011. This article is published with open access at Springerlink.com

After the first description by the French neurologist Georges Gilles de la Tourette in 1885 [3], Tourette Syndrome (TS) has fascinated many clinicians and researchers over the decades. But to date there are relatively few studies on tic disorders (PubMed search 29 January 2011, $n=1,283$ ) and TS $(n=3,762)$ compared to other neurodevelopmental disorders with onset in childhood such as attention/deficithyperactivity disorder (ADHD, $n=18,572$ ) or obsessivecompulsive disorders (OCD, $n=12,558$ ). Thus it is not surprising that the evidence base on etiology, assessment, and treatment is still limited, although there is a high level of clinical experience, particularly in specialized centers.

One of the many reasons for the small base of highquality evidence in diagnosing and treating children and adolescents with TS could be seen in the fact that it has

These guidelines represent the collective view of expert clinicians in the area and are not intended to be rules and conditions since rules and conditions in different countries may vary, such as drug licensing or the availability of therapists.

\section{Roessner $(\bowtie)$}

Department of Child and Adolescent Psychiatry,

University of Dresden Medical School,

Fetscherstrasse 74, 01307 Dresden, Germany

e-mail: veit.roessner@uniklinikum-dresden.de

\section{A. Rothenberger}

Department of Child and Adolescent Psychiatry,

University of Goettingen, Goettingen, Germany

H. Rickards

Department of Neuropsychiatry, Birmingham and Solihull

Mental Health Foundation Trust, Edgbaston, Birmingham, UK

\section{P. J. Hoekstra}

Department of Psychiatry, University Medical Center

Groningen, University of Groningen, Groningen,

The Netherlands only recently become evident that TS and other tic disorders are not rare at all [10] and may negatively impact the quality of life of those affected. This underestimation, in combination with a high rate of relatively mild cases and an often favorable course, with good chance of spontaneous remission, might explain why the necessity for studying TS has been neglected.

The progress of methodologically sound research in the field of TS has been further hampered by the fact that tics show an extremely high variability over time in frequency, severity, complexity, localization and chronicity [5], which requires long-term observations in large samples. In addition it is not straightforward which specialty should deal with TS, a cause for further fragmentation. The core symptoms of TS (i.e., tics) could be seen as a neurologic hyperkinetic movement disorder. However, its neurodevelopmental character and the high rate of different comorbidities, e.g. attention-deficit/hyperactivity disorder (ADHD) or obsessive-compulsive disorders (OCD) suggest its allocation to child and adolescent psychiatry. Although this has triggered a lively interdisciplinary dialogue it might, on the other hand, be one further cause for the lack of strong and large (inter)national research projects in this field.

To overcome this unsatisfactory situation the European Society for the Study of Tourette Syndrome (ESSTS) has been established (originally in 2000 in Copenhagen by Prof. Mary Robertson and others, but re-established in 2008 in Bari after a prolonged silent period). Membership is open to European clinicians and researchers who have an interest in TS. The aims of ESSTS are:

- to enhance understanding of the causes of TS,

- to find effective treatments for TS,

- to share good practice, and

- to stimulate European collaboration in research. 
Therefore we as ESSTS members have decided at our annual meeting in Leiden 2008 to join the forces by developing the first version of European clinical guidelines for TS and other tic disorders. This seemed particularly relevant as ESSTS contains a lot of clinical and research expertise on TS from different disciplines across Europe, while the only three existing Cochrane Reviews on the treatment of tics in TS are all limited to pharmacological treatment $[1,8,9]$ and came to the same conclusion, i.e. that the evidence for efficacy and safety of the studied drugs does not allow firm recommendations. This undesirable situation is also reflected by the fact that to the best of our knowledge in Europe there are currently only national guidelines in Germany $[6,11]$. In addition, while there have been several excellent reviews on the assessment and treatment of TS, these have typically failed to use systematic criteria of study selection [2, 4, 7].

Despite existing wide variations from even tertiary center to tertiary center across Europe, we are proud to present the first version of European clinical guidelines for TS and other tic disorders. We have set up writing groups working on thorough literature review for existing evidence base, adding clinical experience and expertise including intensive and fruitful discussions within ESTSS during the last 2 years. These guidelines hopefully will help clinicians to offer the best clinical service to affected children, adolescents, and adults and inspire clinical researchers as well as politicians to no longer overlook the high burden of tic disorders.

Conflict of interest Commercial firms and governmental organisations did not play a role in, or fund, the development of these guidelines. Hugh Rickards declares that he has no conflict of interest. Veit Roessner: has received lecture fees from Eli Lilly, Janssen-Cilag, Medice, Novartis, he was member of advisory boards of Eli Lilly, Novartis; Aribert Rothenberger (last 3 years): Advisory Board and Speakers Bureau of Lilly, Shire, Medice, Novartis, Research Support from Shire, German Research Society, Schwaabe, Travel Support from Shire, Educational Grant from Shire, Consultant of UCB/Shire, Lilly; Pieter J. Hoekstra: has received lecture fees from Eli Lilly, the University of Frankfurt, Boerhaave, Congress care, and Benecke, has received research funds from ZonMw, NWO (Netherlands Science Foundation), and the European Union (7th Framework Programme); travel support through the European Union (COST action and European Science Foundation); he was member of advisory boards of Eli Lilly and Shire, and paid consultant for Desitin and has been involved in an investigator-initiated trial sponsored by Eli Lilly.

Open Access This article is distributed under the terms of the Creative Commons Attribution Noncommercial License which permits any noncommercial use, distribution, and reproduction in any medium, provided the original author(s) and source are credited.

\section{References}

1. Curtis A, Clarke CE, Rickards HE (2009) Cannabinoids for Tourette's Syndrome. Cochrane Database Syst Rev:CD006565

2. Du JC, Chiu TF, Lee KM, Wu HL, Yang YC, Hsu SY, Sun CS, Hwang B, Leckman JF (2010) Tourette syndrome in children: an updated review. Pediatr Neonatol 51:255-264

3. Gilles de la Tourette G (1885) Etude sur une affection nerveuse caracterisee par de l'incoordination motrice accompagnee d'echolalie et de copralalie. Arch Neurol 19-42:158-200

4. Kurlan R (2010) Clinical practice. Tourette's Syndrome. N Engl J Med 363:2332-2338

5. Leckman JF (2003) Phenomenology of tics and natural history of tic disorders. Brain Dev 25(Suppl 1):S24-S28

6. Muller-Vahl KR, Rothenberger A, Roessner V, Poewe W, Vingerhoets F, Münchau A (2008) Leitlinien für Diagnostik und Therapie: Ticstörungen. In: Diener HC, Putzki N (eds) Leitlinien für Diagnostik und Therapie in der Neurologie. Thieme, Stuttgart, pp 125-129

7. Parraga HC, Harris KM, Parraga KL, Balen GM, Cruz C (2010) An overview of the treatment of Tourette's disorder and tics. J Child Adolesc Psychopharmacol 20:249-262

8. Pierce A, Rickards H (2011) Atypical antipsychotics for Tourette's Syndrome. Cochrane Database Syst Rev (in press)

9. Pringsheim T, Marras C (2009) Pimozide for tics in Tourette's syndrome. Cochrane Database Syst Rev:CD006996

10. Robertson MM (2008) The prevalence and epidemiology of Gilles de la Tourette syndrome. Part 2: tentative explanations for differing prevalence figures in GTS, including the possible effects of psychopathology, aetiology, cultural differences, and differing phenotypes. J Psychosom Res 65:473-486

11. Rothenberger A, Banaschewski T, Roessner V (2007) TicStörungen. In: Deutsche Gesellschaft für Kinder- u. Jugendpsychiatrie PuP (ed) Leitlinien zur Diagnostik und Therapie von psychischen Störungen im Säuglings-, Kindes- und Jugendalter. Deutscher Ärzteverlag, Köln, pp 319-325 